\title{
Liderança nas organizações educativas: a direcção por valores
}

— João Ribeiro Trigo*

- Jorge Adelino Costa**

\section{Resumo}

A liderança constitui um dos temas mais comuns no estudo das organizações em geral, ainda que esta prevalência não tenha atingido o mesmo protagonismo no caso das organizações educativas, de modo particular em alguns contextos geográficos. Não obstante assumirmos neste artigo que as escolas manifestam especificidades relativamente a outras organizações, também reconhecemos que os estudos situados no domínio educacional não podem ficar imunes às contribuições de outras áreas. É neste sentido que invocamos aqui o modelo da Direcção por Valores enquanto proposta que, rompendo como as vertentes mais técnico-instrumentais das teorias tradicionais da gestão, poderá contribuir para uma reflexão compartilhada com a liderança das organizações educativas, de modo especial tendo em conta a conceptualização da liderança como diálogo sobre valores.

Palavras-chave: Liderança. Valores. Gestão escolar.

\section{Leadership in school organisations: management by values Abstract}

Leadership is one of the most common themes in the study of organisations in general, although this prevalence has not reached the same importance in educational organisations, particularly in some geographical contexts. Even though we assume in this article that schools have got some specificities in relation to other organizations, we also recognize that the studies in the education field cannot remain immune to the contributions of other areas. Due to this reason we refer here to the model of Management by Values as a proposal that by breaking away from the more technical-instrumental branches of traditional theories of management, could contribute to a shared reflection with the leadership of educational organisations, specially taking into account the conceptualisation of leadership as a dialogue on values.

Keywords: Leadership. Values. School management.

\footnotetext{
* Diretor do Colégio do Rosário, Portugal. E-mail: jtrigo@colegiodorosario.pt

** Doutor em Ciências da Educação; Professor da Universidade de Aveiro, Portugal. E-mail: jcosta@ua.pt
} 


\section{El liderazgo en las organizaciones educativas: la dirección por valores Resumen}

El liderazgo es uno de los temas más comunes en el estudio de las organizaciones en general, a pesar de esta prevalencia no ha alcanzado el mismo protagonismo en el caso de las organizaciones educativas, en particular en algunos contextos geográficos. Aunque asumamos en este artículo que las escuelas manifiestan especificidades en relación a otras organizaciones, también reconocemos que los estudios desarrollados en el ámbito educativo no pueden permanecer inmunes a las contribuciones de otras áreas. Es por esta razón que referimos aquí el modelo de la Dirección por Valores como propuesta que, rompiendo con las vertientes más técnicoinstrumentales de las teorías tradicionales de la gestión, podrá contribuir para una reflexión compartida con el liderazgo de las organizaciones educativas, especialmente teniendo en cuenta la conceptualización de liderazgo como diálogo sobre valores.

Palabras clave: Liderazgo. Valores. Gestión escolar.

\section{Introdução}

Situando a especificidade das organizações educativas no quadro das organizações em geral, pretendemos com este trabalho abordar a questão da liderança, tema que sempre entusiasmou os estudiosos da ciência organizacional, sendo convicção generalizada entre os mesmos que se está perante uma das condições de sucesso das organizações.

Também nas organizações educativas a liderança tem vindo a assumir um papel de crescente relevo e a ser apontada como uma das chaves para a mudança dos sistemas educativos e das organizações escolares no sentido de as tornar mais eficazes e de aumentar os seus níveis de qualidade. Perrenoud (2003, p. 105) refere dez princípios para tornar os sistemas educativos mais eficazes, entre eles: "chefias que exerçam uma liderança profissional mais do que um controlo burocrático". Também Whitaker (2000, p. 89) face ao acelerado ritmo de mudanças radicais a que as escolas, como todas as organizações, estão a ser submetidas, considera a liderança como o foco crucial para o crescimento e desenvolvimento institucionais. No nosso país, Marçal Grilo, enquanto Ministro da Educação, repetidamente apontou três condições para uma escola de qualidade: existência de um projecto, liderança forte e estabilidade do corpo docente (NETO, 2002, p. 50-52).

Sendo o tema da Liderança muito vasto, não pretendemos de forma alguma ser exaustivos na sua abordagem, pelo que este trabalho convergirá, sobretudo, para a análise de um modelo recente que, não obstante ter surgido no contexto empresarial, nos parece revestir-se de um interessante potencial para a liderança das organizações educativas. Trata-se da Direcção por Valores (DpV), que se apresenta como uma ferramenta de liderança estratégica baseada em valores (GARCÍA; DOLAN, 1997). 
Face às reservas que alguns autores assumem em relação a importar para a escola modelos organizativos e de liderança do mundo empresarial, parece-nos que este modelo de liderança, mesmo para os mais cépticos em ligar ambas as realidades, é uma proposta válida, na medida em que, sendo uma teoria pensada para as empresas, desenvolve conceitos e apresenta preocupações que, na nossa perspectiva, deveriam estar presentes na teoria e na prática da gestão e liderança das organizações educativas, de forma a que estas possam encontrar novos caminhos para a tão desejada como necessária melhoria dos seus níveis de eficácia.

\section{Um mundo de organizações}

No mundo contemporâneo, as organizações são uma inevitabilidade na vida das pessoas, desde que nascem (maternidade, hospital, conservatória do registo civil) até à sua morte (funerária, Igreja, cemitério). Neste sentido, Ferreira, Neves e Caetano (2001, p. xxxi) referem: "Na situação actual, cada um de nós necessita das organizações para viver. [...] Somos, quer queiramos quer não, seres que vivem e trabalham nas organizações, inseridos em unidades organizacionais, intencionalmente construídas e reconstruídas, em permanente evolução e mudança".

Apresentar uma definição de organização não é tarefa fácil, pois trata-se de um conceito complexo, passível de diferentes abordagens e concepções, sendo a literatura muito abundante na matéria'. Todavia, é já clássica a definição proposta por Etzioni (1984, p. 3): "As organizações são unidades sociais (ou agrupamentos humanos) intencionalmente construídas e reconstruídas, a fim de atingir objectivos específicos".

Poderíamos juntar a esta muitas outras definições, mais ou menos complexas, no entanto, talvez seja mais rico e elucidativo utilizar a linguagem metafórica, seguindo uma proposta de Cunha e outros (2004), para ilustrar de forma abrangente diferentes perspectivas sobre as organizações. São cinco as metáforas organizacionais que estes autores nos apresentam: a "organização racional"; a "organização orgânica"; a "organização política"; a "organização cognitiva" e a "organização humana". Os mesmos autores apresentam na sequência destas metáforas uma outra, que denominam como "uma metáfora das metáforas: a organização como amálgama", que nos ajuda a compreender melhor as organizações como realidades complexas e multidimensionais. Segundo os autores, é uma espécie de meta-metáfora "capaz de abarcar e integrar a riqueza das diversas metáforas das organizações". Com a mesma pretendem alertar para que "nenhum acontecimento organizacional deverá ser olhado a partir de uma metáfora, porque as múltiplas perspectivas se fundem e confundem num entrelaçado de objectividade e subjectividade, afecto e cognição, presente e passado, rotina e adaptação" (CUNHA et al., 2004, p. 10).

Apesar das múltiplas metáforas e inúmeras definições, é possível encontrar alguns elementos comuns à maior parte das abordagens. Muñoz Sedano e Roman Perez (1989, p. 41-46) apontam cinco elementos fundamentais do conceito de organização: composição (indivíduos e grupos interrelacionados); orientação para objectivos e fins; diferenciação de funções; coordenação racional intencional e continuidade através do tempo.

\footnotetext{
1 "A definição de organização assume conotações diferenciadas em função das perspectivas organizacionais que lhe dão corpo, já que estamos em presença de um campo de investigação plurifacetado, constituído por modelos teóricos (teorias organizacionais) que enformam os diversos posicionamentos" (COSTA, 1996, p. 12).
} 


\section{A escola como organização educativa}

As variáveis organizacionais da educação só ganharam relevo entre os estudiosos das ciências da educação nas últimas duas décadas, sendo fundamentalmente dois os factores que, a partir de meados dos anos setenta, contribuíram nesse sentido: o "movimento das escolas eficazes", iniciado nos Estados Unidos como reacção ao Relatório Coleman (COLEMAN et al., 1966), e o surgimento de forma consistente e autónoma das "teorias de organização e administração escolar", que vários autores atribuem a uma comunicação de Thomas Greenfield intitulada "Theory About Organization: a new perspective and its implications for schools", numa conferência que decorreu em Inglaterra, em 1974 (COSTA, 1996).

Mais de duas décadas passadas e após a intensa reflexão produzida sobre a matéria, parece ser pacífico considerar a escola como uma organização com aspectos comuns e aspectos distintivos em relação a outras organizações, nomeadamente as de pendor marcadamente económico e empresarial. Nesta linha, Licínio Lima (1992, p. 42) chegou mesmo a afirmar que será "difícil encontrar uma definição de organização que não seja aplicável à escola".

Contudo, se, por um lado, tal análise, no campo educativo em geral, nem sempre se apresentou de forma completamente pacífica (dada a existência de uma dependência inicial da administração e organização escolar em relação a teorias importadas de outras áreas), por outro lado, também se acentua cada vez mais a especificidade da organização escolar, reconhecendo-se o desenvolvimento de diversas perspectivas organizacionais a partir dos contextos escolares. Mais ainda, são os próprios teóricos situados nas áreas empresariais que começaram também a integrar nas suas investigações as organizações escolares (COSTA, 1996).

Licínio Lima (2003, p. 7) sublinha precisamente a importância que a organização educativa vem ganhando enquanto objecto de estudo da sociologia das organizações:

A revalorização da escola como objecto de estudo sociológicoorganizacional tem-se revelado um dos mais interessantes e fecundos desenvolvimentos da pesquisa em educação, ao longo dos últimos anos. Apoiado pela emergência de uma sociologia das organizações educativas e procurando estabelecer pontes com a análise das políticas educacionais, com modelos, imagens e metáforas para a interpretação das organizações sociais formais, e com a crítica às ideologias organizacionais e administrativas, tradicionalmente de extracção empresarial, o estudo da escola vem ganhando centralidade. Trata-se de um processo complexo, mas também muito estimulante, de construção de um objecto de estudo que, no passado, foi frequentemente apagado, ou colocado entre a "espada e a parede", isto é, entre olhares macro analíticos que desprezaram as dimensões organizacionais dos fenómenos educativos e pedagógicos, e olhares micro analíticos, exclusivamente centrados no estudo da sala de aula e das práticas pedagógico-didácticas. 


\title{
A liderança nas organizações educativas
}

Tal como referimos na introdução a este trabalho, a liderança é considerada por muitos autores como um elemento central e verdadeiramente capaz de marcar a diferença, quer nas organizações em geral, quer nas organizações educativas2.

Procuraremos desenvolver esta matéria, passando em revista algumas perspectivas de liderança nas organizações em geral, mas centrando-nos mais especificamente nas organizações educativas. Uma vez que o conceito de liderança, tal como o de organização, é complexo e polissémico, orientaremos a nossa análise em função das perspectivas que apontam no sentido de entenderem a liderança numa linha próxima do modelo que nos propusemos apresentar - a "Direcção por Valores". Curiosamente, embora muitos autores, como veremos, tenham perspectivas coincidentes ou muito próximas da DpV, nenhum refere explicitamente este modelo.

Intencionalmente, e por uma questão de não nos desviarmos demasiado do objectivo deste trabalho, não entraremos nas questões de confronto entre liderança e gestão, liderança e autoridade ou liderança e poder, situando-nos na perspectiva de liderança ao nível de direcção e administração, ou seja, ao nível de quem detém formalmente o poder e a competência para conduzir as organizações.

Introduzindo o que mais à frente desenvolveremos com mais detalhe, apontaríamos como características mais salientes da DpV o claro enfoque nos "valores", nas "pessoas" e no "diálogo" sobre valores. Salvador Garcia (2001 b, p. 1), um dos autores deste modelo, designa este novo líder por pós-convencional e apresenta-o desta forma:

\begin{abstract}
Os numerosos líderes convencionais trabalham - e muito, quase sempre demasiado - administrando hierarquias, recursos e números, enquanto que os escassos líderes pós convencionais - os autênticos líderes - têm o especial valor de pensar de forma diferente, de decidir desenvolver-se como pessoas, de libertar energia criativa nos seus colaboradores, de contribuir para a criação de uma sociedade mais solidária e de criar espaços de diálogo para a verdadeira construção de valores partilhados.
\end{abstract}

Esta perspectiva, como veremos de seguida, está na linha das mais recentes teorias sobre liderança, quer no contexto das organizações em geral, quer no das organizações educativas, em particular.

No que diz respeito às organizações em geral, Chiavenato (1999, p. 51), já um clássico das teorias de administração de empresas e de recursos humanos, escreve assim sobre os valores:

\footnotetext{
2 "O reconhecimento da importância dos processos de liderança no funcionamento das organizações escolares continua, como referíamos no início deste trabalho, na ordem do dia. O quadro da progressiva autonomia, responsabilização e prestação de contas dos estabelecimentos de ensino dá novo alento a esta questão colocando os líderes escolares no centro estratégico de um desenvolvimento organizacional que se pretende coeso, eficaz e de qualidade" (COSTA, 2000, p. 30). Como aponta Nóvoa (1992, p. 26), "a coesão e a qualidade de uma escola dependem em larga medida da existência de uma liderança organizacional efectiva e reconhecida, que promova estratégias concertadas de actuação e estimule o empenhamento individual e colectivo na realização dos projectos de trabalho.
} 
Quando todos os funcionários conhecem a missão e os valores que norteiam o seu trabalho, tudo fica mais fácil de entender, inclusive saber qual o seu papel e como contribuir eficazmente para a organização. [...] E por que a visão é importante nas modernas empresas? Simplesmente pelo fato de que hoje não se controlam mais as pessoas através de regras burocráticas e hierarquia de comando, mas por meio de compromisso com a visão e os valores compartilhados.

Também Daniel Goleman, que introduziu as inovadoras teorias da "Inteligência Emocional", defende a este nível o conceito de liderança primal: "O papel emocional do líder é primal - isto é, vem em primeiro lugar - em dois sentidos. É o primeiro acto de liderança e, ao mesmo tempo, é o mais importante" (GOLEMAN; BOYATZIS; MCKEE, 2002, p. 25). Neste sentido, estes autores apresentam como ideal de liderança a "liderança com ressonância" (própria do líder com inteligência emocional desenvolvida), por oposição a liderança dissonante (sem estar em sintonia). Segundo estes, gerar ressonância, estar sintonizado com os "sentimentos das pessoas", seguir um caminho emocionalmente positivo, pautar-se por valores e despertar os valores e o valor dos que o rodeiam é a tarefa principal de todos os líderes:

Os líderes ressonantes sabem quando devem ser visionários, quando devem ouvir e quando devem dar ordens. São líderes com perspicácia para ver o que é verdadeiramente importante e para definir uma missão que reflicta os valores de quem dirige a organização. São líderes que cuidam naturalmente das relações, que fazem vir à superfície as questões latentes e que criam sinergias humanas em grupos harmónicos. Suscitam relações de lealdade, porque se preocupam com a carreira dos seus subordinados e estimulam as pessoas a dar o melhor de si próprias na prossecução de uma missão que apela a valores compartilhados" (GOLEMAN; BOYATZIS; MCKEE, 2002, p. 267).

Igualmente Rego e Cunha (2004, p. 239), defendendo a "liderança transformacional"3, insistem na questão dos "valores e da ética na liderança":

Subjacente ao modelo está a noção de que a avaliação ética da liderança não pode bastar-se com a análise das suas consequências - é necessário escrutinar o carácter moral do líder, a legitimidade ética dos valores embebidos na visão e na respectiva articulação, e a moralidade dos processos de escolha e acção que líderes e seguidores abraçam e prosseguem. No limite, dois líderes podem adoptar idênticos comportamentos transformacionais e suscitar até idênticas consequências - mas são os valores subjacentes que permitem descortinar que um é autêntico e o outro é pseudo.

Voltemo-nos, agora, para autores mais ligados ao domínio da organização escolar.

\footnotetext{
3 "Por definição, a liderança transformacional é a que produz grandes mudanças/transformações nas organizações, alcandorando-as a níveis superiores de desempenho e ajustando-as adaptativamente às constantes modificações da envolvente" (REGO; CUNHA, 2004, p. 239).
} 
Sergiovanni (2004a; 2004b), desenvolvendo a sua perspectiva de escola como organização especial, por oposição às organizações de tipo empresarial, e reclamando para a mesma também uma liderança especial, que designa como "liderança moral", enfatiza bastante, precisamente, as "pessoas", a "comunidade" e os "valores" como as suas marcas distintivas. Vejamos, algumas ideias do próprio autor:

Precisamos de teorias de liderança que reconheçam que os pais, professores, membros dos órgãos administrativos e alunos têm mais capacidade de tomar decisões baseadas em valores do que em decisões individuais. Em vez de agir de forma calculista e individual, baseados no seu interesse próprio, devemos reconhecer que as pessoas reagem a normas, valores e crenças que definem a qualidade de vida conjunta do grupo que lhes dá significado e importância (SERGIOVANNI, 2004b, p. 37).

“Esta liderança é moral pois sublinha a junção de várias pessoas em torno de uma causa comum tornando a escola numa comunidade formalmente vinculativa. As comunidades vinculativas possuem ideias, princípios e finalidades partilhadas que criam uma poderosa fonte de autoridade para a prática da liderança" (SERGIOVANNI, 2004a, p. 173).

Fullan (2003), ao reflectir sobre as questões da liderança, nomeadamente das escolas, numa cultura e num mundo em permanente mudança, faz uma aproximação às perspectivas de Sergiovanni, quando ao identificar cinco componentes da estrutura conceptual da mudança, apresenta como um desses aspectos o "objectivo moral". Também insiste num aspecto intimamente ligado á questão do diálogo: "as relações". Vejamos:

Em resumo, objectivo moral significa agir com o intuito de provocar uma diferença positiva na vida dos funcionários, clientes e sociedade como um todo. Embora tratando-se de um valor óbvio com o qual muitos de nós nos identificamos, pretendo demonstrar que poderá haver razões evolutivas inevitáveis para que o objectivo moral se torne cada vez mais relevante e que, em qualquer dos casos e em tempos de extrema complexidade, os líderes sejam orientados pelo objectivo moral a bem da sua maior eficácia. [...] (FULLAN, 2003, p. 15).

Se o objectivo moral é a primeira tarefa, então as relações são a segunda, dado que sem elas não vamos a lado nenhum. No passado se perguntássemos a alguém dentro de uma empresa de sucesso o que tinha provocado o êxito, a resposta seria "As pessoas". Mas isso só é parcialmente verdadeiro: na verdade, são as relações que fazem a diferença (FULLAN, 2003, p. 57).

De igual modo, Bolívar (2003, p. 256) reforça o papel das "pessoas" e refere uma liderança que se movimenta num "plano moral":

Entendemos a liderança como uma forma especial de influência tendente a levar os outros a mudarem voluntariamente as suas preferências (acções, pressupostos, convicções), em função de tare- 
fas e projectos comuns. Mediante um conjunto de actividades e projectos, a liderança estimula a partilha de informação, a obtenção dos recursos necessários, a clarificação de expectativas, faz com que as pessoas se sintam membros de uma equipa, ajuda a identificar e a resolver problemas. Para que este exercício de liderança produza efeito costuma movimentar-se de preferência num plano moral: convicções e ideais mediante meios simbólicos e de compromisso com a tarefa educativa.

Robert Marzano (2005, p. 160-164), segundo um estudo muito recentemente publicado em língua portuguesa, como resultado de largos anos de investigação e experiência de trabalho com escolas da América do Norte, destaca como um dos princípios essenciais de uma liderança eficaz para a mudança os "comportamentos específicos que melhoram os relacionamentos interpessoais", enfatizando precisamente a importância do "factor humano" e das relações positivas assentes em valores como dados caracterizadores de uma boa liderança ${ }^{4}$.

Também entre nós, alguns autores defendem uma perspectiva de liderança que coloca em destaque os valores e as pessoas, ou as pessoas unidas em torno de valores. Por exemplo, Barroso (1996, p. 170) apresenta a escola como "construção social", valorizando o "papel dos indivíduos" e afirmando o "primado dos valores sobre os factos":

No que se refere ao estudo da escola, esta abordagem crítica permitiu fazer a ruptura teórica e metodológica, com o paradigma científico-racional que tradicionalmente dominava a análise da sua organização e administração. As escolas passam a ser vistas como construções sociais. É valorizado, na sua análise, o papel dos indivíduos e o contexto social e histórico da sua acção. São abandonadas as metodologias "positivistas" e desenvolvem-se os estudos "etnográficos". São postos em causa os princípios da racionalidade administrativa e defende-se o "primado dos valores sobre os factos", na gestão das organizações educativas.

Quando, há alguns anos atrás, Costa (2000) passava em revista diferentes concepções de liderança nas organizações, deteve-se nos conceitos de escola enquanto "organização pedagógica"5 e na correspondente perspectiva de liderança enquanto "liderança pedagógica", adequada à especificidade das organizações escolares. Neste sentido, evidenciou-se a preocupação com as questões dos "valores" e da "ética" na liderança, bem como com as

\footnotetext{
${ }^{4}$ Nesta linha, MARZANO (2005) cita Blase e Kirby, os quais assinalam três características fundamentais de um líder favoráveis à produção de reformas eficazes: o optimismo (dar esperança nos tempos difíceis); a honestidade (veracidade e consistência entre palavras e acções) e a consideração (orientação para as pessoas ou preocupação com as pessoas).

5 "Parece-nos que a escola, classificada como organização pedagógica, assume uma identidade que vai para além da dimensão de instrução e de ensino e mesmo do próprio conceito de educação. Nesta perspectiva, a escola não é só uma organização democrática, mas uma organização onde as práticas da democracia são objectivo da sua acção; não é só uma escola justa, mas uma organização onde há uma pedagogia da justiça; não é só uma organização aprendente (SENGE, 1990), mas um contexto onde se pratica uma pedagogia da aprendizagem; não é só uma escola autónoma, mas, como escrevia recentemente Lima (1999), na esteira de Paulo Freire, uma organização de pedagogia da autonomia. Ou seja, os próprios modos de organização e os processos de gestão não deverão apresentar-se somente enquanto meios para o desenvolvimento da acção pedagógica mas constituírem-se eles próprios como objectos de acção pedagógica" (COSTA, 2000, p. 27).
} 
"pessoas" e o "diálogo" entre estas, pois a participação, a colaboração, a colegialidade docente, a democraticidade nas decisões, a promoção da autonomia das pessoas e do profissionalismo docente são aspectos centrais neste tipo de processos: "Assim, questões como as da liderança estratégica, da importância do projecto de escola, dos valores e da dimensão ética na liderança, do apelo à liderança transformacional [...] são alguns dos desenvolvimentos necessários desta problemática [...]" (COSTA, 2000, p. 30).

Também, Fátima Chorão Sanches (2000, p. 55) defende a perspectiva da "liderança colegial" nas escolas, desde logo centrando as questões da liderança no "diálogo" e "colaboração entre as pessoas" e introduzindo, também, a necessidade de que esse seja um "diálogo ético, mediado por valores":

Mas o diálogo colegial transcende os objectos gnoseológicos, epistemológicos ou sociológicos inerentes ao ensino e à escola. Também se centra nas questões referentes à responsabilidade deontológica, às implicações éticas do ensino. Nesta dimensão, esta forma de comunicação inter-pares transforma-se em diálogo ético. As práticas de colegialidade envolvem valores que são incompatíveis com relações de competição e de impessoalidade. [...] Uma orientação desta natureza leva os professores a associarem-se em coerência com um conjunto harmonioso de valores: solidariedade, cooperação e reciprocidade comunicativa, respeito e confiança mútua e responsabilidade interdependente. A colegialidade adquire, assim, expressão deontológica fundadora da profissão docente.

Estêvão (2002), numa análise que faz apresentando diferentes metáforas organizacionais para a mudança escolar na perspectiva de globalização, embora com uma abordagem algo crítica, acaba por destacar os aspectos que vimos referindo. Neste seu trabalho, parte da constatação de que actualmente as organizações tendem a ter uma estrutura mais redial, utilizando a metáfora de rede, e identifica novas tendências das organizações: "sistemas de processamento da informação", "organizações flexíveis", "organizações democráticas", "organizações trevo", "organizações teia de aranha", "circuitos ou alianças organizacionais", "redes globais complexas", "organizações curiosas", "organizações aprendentes ou inteligentes". Estas tendências apresentam características comuns

[...] que apontam para outros modos de conceber e gerir as organizações e os seus recursos humanos, para outros modos de integrar (por vezes, de uma forma abstracta) valores desencontrados, para uma nova visibilidade (embora nem todas tenham a mesma solidez e mereçam a mesma credibilidade) de soluções estruturais, para uma visão baseada em objectivos estratégicos [...]. Por outro lado, estas novas morfologias organizacionais (nascidas no campo da gestão) por mais irrealistas, oportunistas e insensatas que possam ser ou parecer, implicam novas configurações de poder, de gestão de conflitos, de liderança, de tempo e de espaço, de identidade, de formas de trabalho, de participação, de coordenação, de controlo, de profissionalismo, de responsabilidade social, de cultura, de verdade e de justiça" (ESTÊVÃO, 2002, p. 18-19). 
Atente-se à ênfase colocada nas pessoas, nas suas relações, nomeadamente as de liderança e poder, e nos valores. Mas Estêvão dá um especial relevo à metáfora da "organização polifónica" (GERGEN; WHITNEY, 1996), na qual a dialogicidade se torna central, dando voz às diferentes (sub)culturas da organização, "ao mesmo tempo que a comunicação se institui na função principal da gestão, podendo estimular as relações intensas até entre actores ausentes" (ESTÊVÃO, 2002, p. 20). É interessante esta perspectiva do "diálogo como marca essencial da gestão", que de alguma forma tem um paralelo na DpV, ao considerar que "a verdadeira liderança é, no fundo, um diálogo sobre valores" (GARCÍA; DOLAN, 1997, p. 5).

Outro autor, Vicente (2004, p. 10), coloca a possibilidade de "ser o modelo organizativo o principal responsável pela ausência de qualidade nas organizações" e por isso entende ser de extrema importância saber qual o paradigma organizativo e de administração e gestão das escolas que potenciará o sucesso do processo educativo. Nesta perspectiva da gestão voltada para as questões da qualidade, para "uma escola com garantia de qualidade", refere o autor:

Uma forte e esclarecida liderança permite e promove o envolvimento e participação crítica de toda a comunidade no desenvolvimento do projecto educativo da escola. Os líderes inovam, centram-se nas pessoas, inspiram confiança, desafiam o poder, têm visão a longo prazo, implicam as pessoas, integram informação. Assim o líder tem como funções: revitalizar a organização, criar novas visões, mobilizar o compromisso com as novas visões e definir a necessidade da mudança" (VICENTE, 2004, p. 143).

Mais uma vez é relevado o "enfoque nas pessoas", nos "valores partilhados" (visão), no desenvolvimento da cultura organizacional com as pessoas e na liderança transformacional que, como veremos, já de seguida, estão presentes igualmente na DpV.

Antes de entrarmos na análise da DpV, um apontamento final, retirado de Fullan (2003, p. 8-9) que, contrariamente a outras perspectivas, valoriza os movimentos de mútua influência entre escolas e empresas:

A liderança nos negócios e na educação têm cada vez mais pontos em comum. Como veremos adiante, o mundo empresarial começa a tomar cada vez mais consciência do quão perigoso é para o sucesso sustentável não ter um objectivo moral. Neste ponto muito terá decerto a aprender com as escolas. Isto porque as escolas começam a descobrir que as novas ideias, a criação e partilha de conhecimento são essenciais para resolver os problemas de ensinoaprendizagem numa sociedade em rápida mudança. $E$, por seu turno, as escolas podem aprender a partir da forma como as melhores empresas inovam e obtêm resultados.

Pareceu-nos importante referir estas perspectivas que, nas questões organizacionais em geral e especificamente nas da liderança, salientam a importância do diálo- 
go entre o mundo das empresas e o mundo das escolas. Fazemo-lo, intencionalmente, imediatamente antes de apresentarmos o modelo da DpV, uma vez que se trata de um modelo de gestão pensado para o mundo das empresas, que nos parece ter potencialidades de aplicação à organização escolar.

\section{A Direcção por Valores (DpV)}

Através do percurso que fizemos, verificámos que há um consenso bastante alargado, embora com especificidades de cada uma das propostas, em considerar a importância dos "valores", das "pessoas" e do "diálogo" numa liderança organizacional capaz de responder a desafios do mundo de hoje, tais como: a globalização, o acelerado desenvolvimento do conhecimento científico e tecnológico, a crescente complexidade, a permanente mudança.

Gestão com pessoas; líderes ressonantes; liderança transformacional; ética na liderança; liderança moral; objectivo moral; primado dos valores sobre os factos; liderança pedagógica; liderança colegial; organização polifónica; gestão com garantia de qualidade - são diferentes formas de traduzir que a ideia de que as organizações actuais, e também a organização escola, precisam de uma liderança que coloque no centro da sua actividade a ética, a moral, os valores, as pessoas, o diálogo e a relação entre pessoas, a adaptabilidade à mudança, o desenvolvimento organizacional, a qualidade, [...] São, também, estas algumas das principais preocupações da Direcção por Valores.

Conceito "Direcção por Valores" foi equacionado em finais dos anos noventa, simultaneamente em Espanha, por Salvador García e Shimon Dolan (1997), com a publicação da sua obra "La Dirección por Valores", e nos Estados Unidos da América, pela obra "Managing by Values", da autoria de Ken Blanchard, Michael O'Connor e Jim Ballard (1997).

Numa definição breve, a "Direcção por Valores" (DpV) é apresentada por García (2002a, p. 4) como um "modo avançado de direcção estratégica e liderança participativa pós convencional baseado no diálogo explícito e democrático sobre os valores partilhados que hão-de gerar e orientar as decisões de acção na empresa".

A "pedra de toque" desta abordagem está pois nos "valores" e nas "pessoas", concretizando-se através do "diálogo" sobre valores partilhados. E é oportuno referir aqui uma citação já anteriormente feita: "a verdadeira liderança é, no fundo, um diálogo sobre valores" (GARCÍA; DOLAN, 1997, p. 5). Todavia, desenvolvamos um pouco mais estas definições, através da perspectiva dos próprios autores:

A DpV é uma nova ferramenta de liderança estratégica. A DpV,
mais do que uma nova moda de dirigir empresas é uma nova
forma de entender e aplicar conhecimentos apresentados pela
Psicologia Social e outras Ciências do Comportamento desde
meados do séc. XX e que muitos dirigentes de todo o mundo
estão começando a praticar de uma forma ou de outra, ainda
que em muitos casos de forma intuitiva e mesmo defeituosa, 
para conseguir sobreviver e diferenciar-se no seu trajecto para o futuro. De facto, a DpV é uma actualização das perspectivas já clássicas do chamado Desenvolvimento Organizacional (DO). Esta actualização pretende algo tão básico como introduzir realmente a dimensão da pessoa dentro do pensamento directivo, não unicamente ao nível de uma "teoria formal", mas na prática diária. [...] A DpV é uma espécie de marco global para redesenhar continuamente a cultura da empresa de forma que se gerem compromissos colectivos através de projectos novos e mobilizadores" (GARCÍA; DOLAN, 1997, p. 4- 5).

Para estes autores, a DpV tem uma finalidade tripla (GARCÍA; DOLAN, 1997, p. 7): simplificar - "absorver a complexidade organizativa derivada das crescentes necessidades de adaptação a mudanças a todos os níveis da empresa"; orientar - "enquadrar a visão estratégica apontando para onde deve ir a empresa no futuro"; comprometer "integrar a direcção estratégica com a política de pessoas, com o fim de desenvolver o compromisso com um rendimento profissional de qualidade no dia-a-dia".

Uma das características fundamentais da DpV, como evolução da Direcção por Instruções (Dpl) e da Direcção por Objectivos (DpO), é a sua "capacidade para absorver complexidade". Segundo os autores (GARCÍA; DOLAN, 1997), nas últimas décadas apareceram quatro tendências organizativas necessárias para a adaptação a um mercado cada vez mais exigente e imprevisível: necessidade de qualidade e orientação para o cliente; necessidade de autonomia e responsabilidade profissional; necessidade de evolução dos chefes a líderes facilitadores; necessidade de estruturas organizativas mais planas e ágeis.

De acordo com o García (2002a, p. 4), podemos verificar como as quatro tendências anteriormente descritas se conjugam com o percurso histórico da Dpl, passando pela $\mathrm{DpO}$, até à $\mathrm{DpV}$. Assim, numa linha evolutiva, o primeiro marco é a Dpl, típica das empresas do início do século e que surge naturalmente ligada aos modelos clássicos de organização e administração industrial e a autores como Taylor e Fayol. Em segundo lugar, surge a $\mathrm{DpO}$, que é uma ferramenta de direcção introduzida por Peter Drucker, na sua obra "The Practice of Management", em meados do século XX. Teve uma evolução para a Direcção Participada por Objectivos (DPpO). Naturalmente, que estas perspectivas representam uma grande evolução face à Dpl, mais no caso da DPpO, pois nelas já existe a preocupação em partilhar com os colaboradores os objectivos do seu trabalho e da organização, como forma de motivação e de quantificação de metas, ou mesmo envolvê-los na definição dos mesmos (na DPpO). Finalmente, a perspectiva da DpV é bastante mais ambiciosa que as anteriores, pois pretende o desenvolvimento de uma cultura organizacional, uma verdadeira identificação dos membros da organização com a sua visão (o para onde vamos?) e com a sua missão (qual a razão de ser? O para quê?), e através desta identificação permitir à organização dar respostas mais eficazes à mudança e, acima de tudo, promover verdadeiramente o desenvolvimento profissional e os valores nos membros da organização.

No Quadro 1, pode ver-se uma tabela comparativa dos três modelos de Direcção. 


\begin{tabular}{|c|c|c|c|}
\hline \multicolumn{4}{|c|}{$\begin{array}{l}\text { DIFERENÇAS ENTRE DIRECÇÃO POR INSTRUÇÕES, } \\
\text { DIRECÇÃO POR OBJECTIVOS E DIRECÇÃO POR VALORES }\end{array}$} \\
\hline & $\mathrm{Dpl}$ & $\mathrm{DpO}$ & $\mathrm{DpV}$ \\
\hline $\begin{array}{l}\text { Situação de } \\
\text { aplicação } \\
\text { preferencial }\end{array}$ & $\begin{array}{l}\text { Rotina ou } \\
\text { emergências }\end{array}$ & $\begin{array}{l}\text { Complexidade } \\
\text { moderada. } \\
\text { Produção relativamente } \\
\text { estandardizada. }\end{array}$ & $\begin{array}{l}\text { Necessidade de } \\
\text { criatividade para a } \\
\text { resolução de } \\
\text { problemas complexos }\end{array}$ \\
\hline $\begin{array}{l}\text { Nível médio de } \\
\text { profissionalização } \\
\text { dos membros da } \\
\text { organização }\end{array}$ & $\begin{array}{l}\text { Baixa escolaridade } \\
\text { (direcção de } \\
\text { operários) }\end{array}$ & $\begin{array}{l}\text { Profissionalização } \\
\text { média (direcção de } \\
\text { empregados) }\end{array}$ & $\begin{array}{l}\text { Alto nível de } \\
\text { profissionalização } \\
\text { média (direcção de } \\
\text { profissionais) }\end{array}$ \\
\hline $\begin{array}{l}\text { Autonomia e } \\
\text { responsabilidade }\end{array}$ & Baixa & Média & Alta \\
\hline Tipo de destinatário & Utente-comprador & Utente - cliente & $\begin{array}{l}\text { Cliente com critério e } \\
\text { liberdade de escolha }\end{array}$ \\
\hline $\begin{array}{l}\text { Tipo de oferta de } \\
\text { produtos }\end{array}$ & $\begin{array}{l}\text { Monopolista. } \\
\text { Estandardizada }\end{array}$ & Segmentada & $\begin{array}{l}\text { Altamente } \\
\text { diversificada e mutável }\end{array}$ \\
\hline $\begin{array}{l}\text { Tolerância à } \\
\text { ambiguidade }\end{array}$ & Baixa & Média & Alta \\
\hline $\begin{array}{l}\text { Estabilidade do } \\
\text { contexto }\end{array}$ & Contexto estável & $\begin{array}{l}\text { Contexto } \\
\text { moderadamente mutável }\end{array}$ & Contexto muito mutável \\
\hline Organização social & Capitalista - industrial & Capitalista - pós industrial & Pós capitalista \\
\hline Tipo de liderança & Dirigista tradicional & $\begin{array}{l}\text { Administrador de } \\
\text { recursos }\end{array}$ & $\begin{array}{l}\text { Legitimador de } \\
\text { transformações }\end{array}$ \\
\hline $\begin{array}{l}\text { Tipo de estrutura } \\
\text { organizativa }\end{array}$ & $\begin{array}{l}\text { Piramidal com } \\
\text { múltiplos níveis }\end{array}$ & $\begin{array}{l}\text { Piramidal com poucos } \\
\text { níveis }\end{array}$ & $\begin{array}{l}\text { Redes, alianças } \\
\text { funcionais, estruturas } \\
\text { de equipas de projecto }\end{array}$ \\
\hline Filosofia de controlo & $\begin{array}{l}\text { Controlo por } \\
\text { supervisão descendente }\end{array}$ & $\begin{array}{l}\text { Controlo por estímulo do } \\
\text { rendimento profissional }\end{array}$ & $\begin{array}{l}\text { Potenciação do auto- } \\
\text { controlo das pessoas }\end{array}$ \\
\hline $\begin{array}{l}\text { Propósito da } \\
\text { organização }\end{array}$ & Manter a produção & Optimizar resultados & $\begin{array}{l}\text { Melhoria constante } \\
\text { dos processos }\end{array}$ \\
\hline $\begin{array}{l}\text { Alcance da visão } \\
\text { estratégica }\end{array}$ & Curto prazo & Médio prazo & Longo prazo \\
\hline $\begin{array}{l}\text { Valores culturais } \\
\text { essenciais }\end{array}$ & $\begin{array}{l}\text { Produção } \\
\text { quantitativa, } \\
\text { fidelidade, } \\
\text { conformidade, } \\
\text { cumprimento, } \\
\text { disciplina }\end{array}$ & $\begin{array}{l}\text { Racionalização, } \\
\text { motivaçãa, eficiência, } \\
\text { medição de resultados }\end{array}$ & $\begin{array}{l}\text { De senvolvimento, } \\
\text { p a r t i c i p a ç ã o, } \\
\text { aprendizagem contínua, } \\
\text { criatividade, confiança } \\
\text { mútua, compromisso }\end{array}$ \\
\hline
\end{tabular}

Quadro 1 - Direcção por Instruções, Direcção por Objectivos e Direcção por Valores. Fonte: adaptado de García e Dolan (1997, p. 30-31). 
Associadas a estas três perspectivas de liderança, encontramos diferentes concepções sobre: modelos de sociedade, modelos de organização sócio-económica, concepção da pessoa e desenvolvimento da consciência moral do líder (GARCÍA, 2001a, p. 16).

Neste sentido, o modelo de sociedade evolui da percepção micro para a macro: do "paroquialismo", também designado pelo autor por "provincianismo", simbolizando a pequena sociedade fechada; para a "globalização", hegemónica, da alta tecnologia e da informação e finalmente para o "cosmopolitismo", que o autor caracteriza assim:

\begin{abstract}
O cosmopolitismo é a perspectiva de pertença de todo o indivíduo à humanidade, que se entende como a única comunidade moralmente significativa para além dos particularismos nacionalistas. Este pensamento universalista vai para além da globalização como neohegemonia norte americana. É tolerância, empatia, sensibilidade para as diferenças. A sensibilidade cosmopolita é solidária e de mentalidade aberta (open mind), correspondendo aos esquemas da 'sociedade aberta' de Popper" (GARCIA, 2001 a, p. 17).
\end{abstract}

Quanto à organização sócio-económica, a evolução faz-se de um "capitalismo rígido" e ainda rudimentar, da era industrial, passando por um "capitalismo" mais "flexível" e também mais funcional, que começa a atender a outros aspectos que não o meramente económico e a dar importância às pessoas e ao seu envolvimento com os objectivos da organização, para um "capitalismo sensível" e solidário, mais um conceito que clarificamos com o pensamento do próprio autor:

\begin{abstract}
A DpV é a dimensão organizativa de um capitalismo sensível desenvolvido por empreendedores com valores. Se quer continuar a ser legítimo, o globalitário sistema capitalista actual deve decidir evoluir para uma sensibilidade de cidadania cosmopolita a nível internacional, para uma Direcção por Valores a nível organizativo e para um empreendedorismo com valores a nível individual (GARCIA, 2001a, p. 9).
\end{abstract}

Relativamente à concepção de pessoa, a evolução parte da perspectiva de "pessoa como máquina", associada aos modelos da era industrial de inícios do século XX, para a visão de "pessoa como recurso", até à perspectiva condizente com a DpV: a "pessoa como fim". Há aqui notoriamente influências das correntes humanistas, que não são negadas pelos autores:

Na sua obra central de 1960, 'The Human Side of Entrerprise', McGregor já definia o dirigente humanista como o dirigente profissional que, com o fim de dirigir pessoas e obter resultados empresariais, aplica conhecimentos derivados das ciências humanas, tais como a psicologia social, a antropologia, a ciência política ou a filosofia. As ciências económicas são claramente insuficientes para saber dirigir pessoas e projectos. Engenharia e humanidades são mutuamente necessárias. Não podemos voar em aviões de papel nem os aviões servem para dar sentido ao voo pela vida. Não só necessitamos de mais praxis, mas também de mais ética e mais poiética (GARCIA, 2001a, p. 6). 
Quanto à consciência moral do líder, o autor entende que a mesma pode ter um impacto significativo no conjunto do capital axiológico do sistema organizativo que lidera. Na sua análise segue o modelo dos três níveis de desenvolvimento da maturidade da consciência moral da pessoa, desde a infância até à idade adulta, proposto por Lawrence Kohlberg (1981). Nesta perspectiva a "consciência moral pré-convencional" corresponde ao raciocínio moral das crianças pequenas, que julgam o que está correcto do ponto de vista dos seus próprios interesses imediatos: correcto é o que evita o castigo, o que segue as directrizes emanadas da autoridade e o que proporciona benefício imediato. A "consciência moral convencional" corresponde a enquadrar as questões morais segundo as normas, expectativas e interesses da ordem social estabelecida - o líder convencional não chega a ser um líder é mais um gestor do "status quo". $\bigcirc$ líder "pós-convencional", aquele que se enquadra na perspectiva da DpV, é capaz de, com critério próprio, distinguir entre as normas de seu envolvente, os valores instrumentais, e os princípios éticos que são universalmente defensáveis, como valores últimos. Daí o líder pós-convencional ser cosmopolita, estar aberto às questões que envolvem toda a humanidade: "O líder pós-convencional pensa e actua de forma transformadora, para além do que se considera habitual nos seus grupos de referência, e fá-lo de acordo com a sua própria consciência moral baseada em crenças e valores cosmopolitas de tipo ético, prático e poiético" (GARCÍA, 2001b, p. 10).

O líder pós-convencional tem um perfil humanamente evoluído, não se governa pelas convenções ou crenças dominantes no seu meio ambiente, mas pela suas próprias convicções, pela sua visão do mundo, tem capacidade para transformar as coisas e dar pleno sentido à sua vida e à dos outros. Como tal, torna-se inspirador e legitimador de diálogos capazes de construir a confiança, a sensibilidade e a liberdade. Neste sentido, o autor desenvolve a tese de que o líder pós-convencional é aquele que "faz a gestão do medo" em si e nos outros: "Atrevamo-nos a contemplar uma nova proposta de liderança conscientemente centrada na liberdade da pessoa e na sua dignidade. Sem ignorar a existência de circunstâncias económicas, biológicas ou culturais, consideremos a necessidade de contrariar tanto discurso intimidatório (chamado "realista" por muitos) sobre o peso do contexto, da estrutura, da lamentável natureza humana e da mera inércia" (GARCÍA, 2001 b, p. 1).

Tratando-se de um modelo de Direcção por Valores, naturalmente que estes, quer na sua conceptualização, quer na sua análise mais pormenorizada, nomeadamente através do estabelecimento de diferentes categorias, são objecto de intensa teorização por parte dos autores. Sem levarmos a fundo esta questão, por inadequação a um trabalho desta natureza, deixamos alguns apontamentos principais.

Os autores partem da noção de valores como sendo "o resultado de crenças internalizadas sobre como devemos actuar" (DOLAN; GARCÍA; NAVARRO, 2002, p. 4), associando-os à liberdade humana, à capacidade de distinguir e escolher o bem ou o mal. Os valores são considerados a alma da empresa e surgem associados à sua visão e missão:

Definitivamente, a visão, a missão e os valores partilhados são a alma da empresa, sua moral, o seu espírito, a sua identidade diferenciadora, a sua poesia. São activos humanistas, não tangíveis 
porém de vital importância para animar e dar coerência e moral ao esforço de alto rendimento das pessoas na empresa. A falta de valores verdadeiramente dialogados e indutores de sentido para a acção cria empresas desalmadas, desumanizadas, fragmentadas e prosaicas, pessoas desanimadas, projectos inanimados, e equipas desmoralizadas. Esta falta de alma gera empresas às quais para a grande maioria representa um enorme esforço voltar segunda-feira pela manhã (DOLAN; GARCÍA; NAVARRO, 2002, p. 2).

Subjacente a esta perspectiva está a de estabelecer um equilíbrio dinâmico entre dois grandes grupos de valores ou princípios de acção na vida organizativa: entre a orientação "prosaica", voltada para o controlo, que se liga a valores relacionados com eficácia de gestão (eficiência, responsabilidade, cumprimento, optimização, obediência), e a orientação "poética", voltada para o desenvolvimento de novas perspectivas de acção, que se liga a valores dirigidos para a emoção e a criação (confiança, liberdade, iniciativa, criatividade, flexibilidade, entusiasmo, alegria). Trata-se, no fundo de integrar economia com humanismo.

Nesta linha, GARCÍA (2001a, p. 12) refere como enfoque metodológico da DpV um "modelo triaxial"6 de análise que agrupa os valores em três dimensões, que desejavelmente devem estar o mais equilibradas possível: o eixo de valores "práxicos" (ligados à prática) ou de controlo; o eixo de valores "poiéticos"7 (emocionais e criativos) e o eixo dos valores "éticos", eixo central em torno do qual giram os outros dois. $\bigcirc$ modelo triaxial da Direcção por Valores visa a criação de empresas "eutópicas" $^{\prime \prime}$ : "chegou, pois, o momento de que o grito utópico de que 'outro mundo é possível' incorpore o realismo eutópico de que 'outra empresa é possível" (GARCÍA, 2003, p. 1). As empresas "eutópicas" têm uma tripla responsabilidade: equilíbrio económico, ético e emocional. Naturalmente que a "alma" deste modelo assenta sobretudo nos eixos dos valores éticos e "poiéticos", pois "os valores práxicos convencionais, que dominam o mundo da empresa, estão a perder o seu poder hegemónico para dar sentido à acção" (GARCIA, 2001a, p. 3). Como que resumindo e justificando todo o sentido deste modelo, assim escreve o autor:

O homo tecnoeconomicus alcançou o seu tecto evolutivo de máxima eficiência, de felicidade e de sentido para a acção. Há que explorar e aplicar novos modos de pensar e fazer as coisas nas empresas mais evoluídas; quer dizer, mais éticas e mais 'poiéticas', que questionem e ampliem o modelo dominante de 'progresso' e de 'criação de valor' propugnado pelo pragmatismo das nações no poder mundial (Estados Unidos, Alemanha, Japão [...]) e suas seguidoras. Chegou a hora da ética empresarial, de libertar o potencial criativo das pessoas e de pensar em novas formas de lide-

\footnotetext{
${ }^{6}$ Modelo triaxial porque se baseia em três eixos de valores (axiologia é a ciência que estuda os valores), os quais no seu conjunto constituem o "capital axiológico da empresa", no fundo a sua verdadeira identidade.

7 A palavra poesia provém do grego "poiesis", que significa gerar, desenvolver. É a partir daqui que os autores criam o conceito de valores "poiéticos": valores "geradores de ética".

${ }^{8} \mathrm{O}$ conceito "eutópico" deriva da conjugação de "eu", prefixo que exprime a ideia de bondade, e "topos" que na raiz grega significa lugar. Empresa eutópica = lugar bom para trabalhar, "onde as pessoas são o fim".
} 
rança e de empreendedorismo baseadas numa consciência moral pós convencional. [...] A perdurabilidade e desenvolvimento do sistema capitalista passam pela sua humanização: passa por entender e aplicar o valor do respeito à pessoa e ao seu meio ambiente. [...] A turbulência e incerteza do ambiente socio-económico actual deve enfrentar-se construindo uma 'alma' organizativa que dê sentido humano à acção (GARCIA, 2001 a, p. 4).

Para finalizar, demos conta de um breve apontamento sobre uma das virtualidades do modelo, realçada pelos autores, que nos parece interessante, atendendo às características e exigências do mundo em que vivemos: "o valor dos valores como ordenadores do caos e da incerteza" (GARCIA, 2002b, p. 1). Este aspecto, que já atrás foi tocado ao referirmos a capacidade do modelo para absorver complexidade, dá-nos conta que a pessoa ou as organizações, habituadas a esquemas convencionais, com elevados níveis de ordem e controlo, lidam mal com a incerteza e mudança, tendendo a desenvolver mecanismos de agressividade defensiva. Tal estado de espírito, levado ao extremo, conduz à aversão ao risco, à resistência à mudança, à inibição da criatividade própria e da dos outros. Em situações de alta complexidade e de máxima vitalidade criativa, situadas "na fronteira do caos", os valores individualmente assumidos ou compartilhados, quando em contextos sociais, são estratégicos para lidar com a incerteza e mudança, uma vez que proporcionam, à pessoa e às organizações, profissionalismo, abertura crítica e ética. Estes valores, no seu conjunto, geram liberdade e confiança, dotando as pessoas e as organizações de capacidade para, evitando o medo e a ansiedade, lidarem com a incerteza e a mudança.

\section{Considerações finais}

A Direcção por Valores, apesar de pensada para o mundo empresarial, não se afasta muito, nos seus pressupostos essenciais, de algumas concepções de liderança pensadas para a organização escolar que tivemos a oportunidade de apresentar ao longo deste trabalho. Algumas delas, associam liderança a moral: a "liderança moral" defendida por Sergiovanni, a liderança com "objectivo moral" defendida por Fullan, o "plano moral" referido por Bolívar. Somos de opinião, contudo, que a terminologia dos valores pode apresentar vantagens em relação à terminologia da moral. Desde logo, está mais perto da linguagem corrente das escolas: um dos objectivos centrais da escola é "a educação para valores". Por outro lado, a moral tende a confundir-se, embora erradamente, com a religião, ou pior ainda a associarse a posições rígidas, de intolerância e de puritanismo, também erradamente, porque esse é o domínio do moralismo e não da moral. Estas questões terminológicas, sendo acessórias, devem contudo merecer alguma atenção, pois as representações sociais que se fazem de determinados conceitos, mesmo que erradas, podem acabar por condicionar as pessoas e a realidade.

Deixando de lado juízos comparativos, permitimo-nos distinguir neste modelo alguns aspectos cruciais:

- Raízes acentuadamente humanistas - a virtude de entender a pessoa e o valor da pessoa e da sua dignidade como fim e não como mero recurso; 
Clareza, ainda que um pouco simplificadora, com que situa o evoluir histórico das perspectivas sobre direcção e liderança, ao fazer o confronto entre Dpl, DpO e DpV;

- Capacidade de introdução, num campo já tão explorado, de alguns conceitos inovadores e com bastante conteúdo e riqueza semântica: valores "poiéticos"; empresas "eutópicas"; liderança pós-convencional; cosmopolitismo (em contraponto com globalismo), capitalismo sensível ou solidário;

- Preocupações sociais, procurando ultrapassar alguns impasses do modelo capitalista e sugerindo pistas de respostas mais solidárias;

- Capacidade de resposta à complexidade, incerteza e mutabilidade do mundo contemporâneo (valores como ordenadores do caos).

Quanto ao seu potencial para aplicação à organização escolar, sintetizando, apontamos alguns aspectos que nos surgem como mais evidentes e merecedores do nosso destaque:

- Desde logo o foco nos valores. Essa deve ser inquestionavelmente também a grande missão da escola: educar para uma cidadania com valores, de reconhecimento e de respeito pela dignidade de todos os seres humanos. Têm aqui necessariamente lugar a solidariedade e a educação para a justiça, desenvolvendo o sentido de responsabilidade pela transformação das estruturas de injustiça no nosso mundo.

- A perspectiva pós-convencional de entender a "liderança como um diálogo sobre valores" que, não sendo pensada para a escola, é bastante pedagógica e educativa. A escola, sendo um espaço de relações permanentes entre pessoas, onde se exercem muitas lideranças, aos mais diversos níveis, nomeadamente no espaço sala de aula, beneficiaria desse diálogo aberto, democrático, fundado em valores compartilhados e no reconhecimento do valor supremo da pessoa. Entendemos esta perspectiva como pedagógica e vital para a transformação e desenvolvimento de uma organização ainda muito marcada, na generalidade dos casos, pela ausência de verdadeiras lideranças (por omissão, por burocratização, por falta de formação ou de recrutamento adequado, [...]) e por práticas acentuadamente individualistas, no relacionamento entre professores, e directivas, no relacionamento com os alunos, por oposição a pedagogias mais construtivistas. Há de facto um défice de diálogo e de relações positivas.

- A questão do desenvolvimento de uma cultura organizacional, assente na visão, missão e valores partilhados, essencial para algo que para muitos já vai sendo considerado uma utopia ou que existe apenas no domínio das retóricas ou das práticas simbólicas, mas que entendemos ser um objectivo a perseguir com firmeza: a construção de verdadeiras comunidades educativas, cimentadas por laços de respeito, consideração, mesmo de afectividade e, necessariamente, pela construção partilhada de objectivos comuns.

- A adequação dos valores para ordenar, de forma livre, criativa e flexível o caos (a permanente instabilidade e mudança), ferramentas, sem dúvida, essenciais para a escola e para os seus agentes educativos. Se o mundo de hoje tem a marca da mudança e da instabilidade, mais do que ninguém as crianças e jovens são "feitos dessa argamassa", não sejam eles, por natureza, seres em crescimento e, portanto, em permanente mudança e, por outro lado, os que mais facilmente integram e se deixam influenciar pelas mudanças, incertezas e perplexidades do mundo que os rodeia. Apresentar um referencial de valores, ou, mais importante ainda, serem os 
educadores pelas suas convicções e exemplo referenciais de valores, que contribuam para ordenar esse caos, permitirá às crianças e jovens encontrarem pistas de crescimento harmonioso e equilibrado, sendo este um grande contributo que todas as escolas e professores poderão dar para o desenvolvimento pessoal dos seus alunos.

- Toda a perspectiva positiva, de orientação poética ou "poiética", que este modelo nos apresenta, para além do seu valor essencial, tem também algo de pedagógico: o optimismo que permite a "gestão do medo", da apatia, da fuga; o entusiasmo capaz de dar um suplemento de "alma" à nossa acção e à nossa vida; a realização pessoal e profissional; alguma "utopia" que permita encontrar criativamente soluções para alguns "becos sem saída" da "realidade" do mundo em que vivemos... Só organizações educativas, cujo ambiente permita a libertação da energia criativa das suas pessoas, desenvolvendo os seus valores e o seu valor, terão condições para ajudar a libertar todo o potencial nos seus alunos.

Naturalmente que este modelo também terá as suas limitações, como todos os modelos ou propostas, pois não acreditamos em modelos perfeitos ou acabados, uma vez que tudo pode continuamente ser melhorado. Contudo, uma vez que esse era o objectivo desta análise, concentrámo-nos na identificação das potencialidades do modelo e não nas suas limitações.

Concluindo, acreditamos que uma liderança que se inspire em valores, comunique e "dirija" através de valores - que seja capaz de mobilizar os membros da comunidade para um diálogo em torno de valores, desenvolvendo a partir daí uma cultura própria, o seu próprio valor e o valor em todos os membros, que os leve, inclusive, a voltaremse para os outros e a serem "activos" na construção de uma sociedade e de um mundo melhores - será verdadeiramente facilitadora e inspiradora das mudanças necessárias ao aumento da qualidade e eficácia das instituições educativas.

\section{Referências}

BARROSO, J. (Org.). O estudo da escola. Porto: Porto Editora, 1996.

BOLÍVAR, A. Como melhorar as escolas: estratégias e dinâmicas de melhoria das práticas educativas. Porto: ASA, 2003.

CHIAVENATO, I. Gestão de pessoas: o novo papel dos recursos humanos nas organizações. Rio de Janeiro: Elsevier, 1999.

COLEMAN, J. S. et al. Equality of educational opportunity. Washington: US Government Printing Office, 1966.

COSTA, J. Imagens organizacionais da escola. Porto: ASA, 1996.

- Lideranças nas organizações: revisitando teorias organizacionais num olhar cruzado sobre as escolas. In: SIMPÓSIO SOBRE ORGANIZAÇÃO E GESTÃO ESCOLAR, 1., Aveiro, 2000. Actas... Aveiro: Universidade de Aveiro, 2000. 
CUNHA, M. et al. Manual de comportamento organizacional e gestão. Lisboa: RH Ed., 2004.

DOLAN, S.; GARCÍA, S.; NAVARRO, C. La construcción del alma de la empresa: visión, misión y valores compartidos. In: MANAGEMENT espanõl: los mejores textos. Barcelona: Ariel, 2002. Disponível em: < http:// www.managementbyvalues.com/ docs/vision.pdf>. Acesso em: 9 fev. 2005.

ESTÊVÃO, C. Globalização, metáforas organizacionais e mudança educacional: dilemas e desafios. Porto: ASA, 2002.

ETZIONI, A. Organizações modernas. São Paulo: Pioneira, 1984.

FERREIRA, C.; NEVES, J.; CAETANO, A. Manual de psicossociologia das organizações. Lisboa: McGraw-Hill, 2001.

FULLAN, M. Liderar numa cultura de mudança. Porto: ASA, 2003.

GARCÍA, S. La dirección por valores (DpV) como herramienta de liderazgo postconvencional. In: MANAGEMENT espanõl: los mejores textos. Barcelona: Ariel, 2002a. Disponível em: <http://www.managementbyvalues.com/ docs/ dpv.pdf>. Acesso em: 9 fev. 2005.

La empresa "eutópica" y su triple responsabilidad económica, ética y... emocional: casi 100 preguntas y una respuesta para el cambio. In: CONGRESO DE DIRECTIVOS DE RR.HH Y MANAGEMENT, 2003, Madrid; CONVOCATÓRIA DEL MANAGER BUSINESS FÓRUM, 7., Madrid. Trabajos... Madrid: Manager Business Fórum, 2003. Disponível em: <http://www.managementbyvalues.com/ docs/CongresoDirectivosRRHH.pdf>. Acesso em: 9 fev. 2005.

. Ética, liderazgo postconvencional y creatividad. Dirección y Progresso,

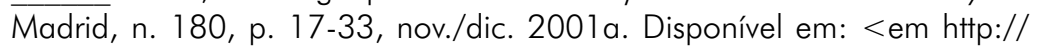
www.managementbyvalues.com/docs/ eticaliderazgocreatividad.pdf>. Acesso em: 9 fev. 2005.

. El valor de los valores como ordenadores del caos y la incertidumbre. Recursos Humanos, n. 16, p. 44-49, 2002b. Disponível em: <http:// www.managementbyvalues.com/ docs/caos.pdf $>$. Acesso em: 9 fev. 2005.

. El valor del líder postconvencional: la gestión del miedo. In: LIDERANDO con emoción. Madrid: Soluziona-Grieker Orgemer, 2001b. Disponível em: <http:// www.managementbyvalues.com/ docs/Liderandoemocion.pdf>. Acesso em: 9 fev. 2005.

GARCÍA, S.; DOLAN, S. La Dirección por Valores (DpV): el cambio más allá de la dirección por objectivos. Madrid: McGraw-Hill., 1997.

GOLEMAN, D.; BOYATZIS, R.; MCKEE, A. Os novos líderes: a inteligência emocional nas organizações. Lisboa: Gradiva, 2002. 
KOHLBERG, L. Essays on moral development. San Francisco: Harper and Row, 1981. v. 1.

LIMA, L. A escola como organização e a participação na organização escolar: um estudo da escola secundária em Portugal (1974-1998). Braga: Instituto da Educação, Universidade do Minho, 1992.

. A escola como organização educativa: uma abordagem sociológica. São Paulo: Cortez, 2003.

MARZANO, R. Como organizar as escolas para o sucesso educativo: da investigação às práticas. Porto: ASA, 2005.

MUÑOZ SEDANO, A.; ROMAN PEREZ, M. Modelos de organizacion escolar. Madrid: Cincel, 1989.

NÓVOA, A. Para uma análise das instituições escolares. In: NÓVOA, A. (Coord.). As organizações escolares em análise. Lisboa: Dom Quixote, 1992.

NETO, D. Difícil é sentá-los. Lisboa: Oficina do Livro, 2002.

PERRENOUD, P. Dez princípios para tornar o sistema educativo mais eficaz. In: AZEVEDO, J. (Coord.). Avaliação dos resultados escolares: medidas para tornar o sistema mais eficaz. Porto: ASA, 2003.

REGO, A.; CUNHA, M. A essência da liderança: mudança $x$ resultados $x$ integridade: teoria, prática, aplicações e exercícios de autoavaliação. Lisboa: Ed. $\mathrm{RH}, 2004$.

SANCHES, F. Da natureza e possibilidade da liderança colegial das escolas. In: SIMPÓSIO SOBRE ORGANIZAÇÃO E GESTÃO ESCOLAR, 1., Aveiro, 2000. Actas... Aveiro: Universidade de Aveiro, 2000.

SERGIOVANNI, T. O mundo da liderança: desenvolver culturas, práticas e responsabilidade pessoal nas escolas. Porto: ASA, 2004a.

SERGIOVANNI, T. Novos caminhos para a liderança escolar. Porto: ASA, 2004b.

VICENTE, N. Guia do gestor escolar: da escola de qualidade mínima garantida à escola com garantia de qualidade. Porto: ASA, 2004.

WHITAKER, P. Gerir a mudança nas escolas. Porto: ASA, 2000.

Recebido em: 09/09/2008

Aceito para publicação em: 03/11/2008 